\title{
Re-visiting the educational environment of a metropolitan medical school in Sri Lanka with special emphasis on clinical learning
}

\author{
Karunaratne, W.C.D. \& Chandratilake, M.N
}

\begin{abstract}
Introduction: Clinical competence is central to effective and efficient medical practice. Thus, clinical training lies at the heart of undergraduate medical education. This study examined medical undergraduates' perceptions of their clinical learning environment as a means to identify service gaps and work towards remediation.

Methods: The DREEM (Dundee Ready Educational Environment Measure) questionnaire was used to measure student perceptions on their clinical learning environment from 262 medical undergraduates at different seniority levels of clinical training. Additionally, two open ended questions were asked.

Results: Overall student perception reflected as overall DREEM score, was more positive on the clinical learning environment. However, sub domain scores revealed "Students' perception of learning" significantly increases and "Students' perception of teachers" significantly reduces with advancing years of seniority. Analysis of individual items under each sub-domain revealed problem areas having scores of 2 or less representing all subscales. The thematic analysis of qualitative comments resulted in several themes verifying and elaborating more on quantitative findings.

Conclusions: Despite overall positive student perception scores on the existing clinical learning environment, detailed analysis revealed several problem areas representing all sub domains at a variable degree. Majority of the problems were related to the domain on "students' perception of teachers". Several other issues related to clinical rotations and the undergraduate medical curriculum was identified creating a vicious circle of ineffective student learning and poor clinical performance. Therefore, the DREEM questionnaire along with qualitative comments could be considered as a cost effective means of obtaining a broader understanding of any learning environment and could be adopted by an organization to add more depth into quantitative analysis.
\end{abstract}

Key words: Clinical learning environment, DREEM, Dundee Ready Educational Environment Measure

\section{Background}

The 'educational environment' broadly embraces numerous factors affecting effective student learning and hence termed 'the background on which the curriculum resides' (Maudsley, 2001, p.432).

Medical Education Centre, Faculty of Medicine, University of Kelaniya, Sri Lanka

Corresponding author:

WCD Karunaratne

Medical Education Centre, Faculty of Medicine,

University of Kelaniya,

PO Box 6, Thalagolla Road, Ragama,

Sri Lanka
Email:dilmini@kln.ac.lk

Many researchers have explored the concept using different tools (Roff, 2005; Roff et al., 2005; Janz \& Pyke, 2000), which highlights its importance in medical education. Many of these tools attempt to capture the expectations of students, effects of changing demographics of students and the impact of curricular changes and interventions.

The DREEM inventory (Dundee Ready Educational Environment Measure) developed by Roff et.al (1997) has been adopted by many 
medical schools globally as a means of measuring the educational environment. It has also been used in few medical schools in Sri Lanka (Lokuhetty et al., 2010; Jiffry et al., 2005; Chandratilake \& Silva, 2009). However, in almost all instances it has been used to measure the academic environment in nonclinical settings. A limited number of studies have adopted it for measuring the clinical learning environment (Bunyan et al., 2011; Varma et al., 2005).

Clinical training of medical undergraduates is at the heart of their undergraduate education. Clinical exposure not only allows them to apply theoretical knowledge in to practice but also enables them to appreciate the professional roles, responsibilities and ethics in practicing medicine. Therefore, the need to maintain and flourish a positive clinical learning environment catering to student needs is a mandatory component of medical training. Despite considerable emphasis, clinical performance of novice medical graduates is a concern expressed by many medical schools globally and in the local setting (Wright et al., 2012; Spencer, 2003).

The medical school where the study is conducted provides gradually increasing clinical exposure to medical undergraduates commencing from third year until the final (fifth) year of training. Initial clinical rotations are organized as 4 weeks training for the main clinical specialties (Medicine, Surgery, Paediatrics and Gynaecology \& Obstetrics) and 2 weeks for other sub-specialty training (e.g. Cardiology, Orthopaedics). During the fourth year there is more extensive exposure of eight weeks for each main clinical specialty, increasing further to 12 weeks towards the final year. Despite extensive clinical training offered by the institution, teachers' distress on student performance during clinical rotations remains considerably high.

Therefore, we used the DREEM inventory in the current study to measure the clinical learning environment of the medical school in order to identify quality gaps and to work towards remediation. It was also assumed that this will provide some insight into comparison of the current educational environment with the previous measure which was obtained a decade ago using the same tool at the time of curricular change in the medical school.

\section{Methods}

A quantitative study was conducted using the self-administered DREEM (Dundee Ready Educational Environment Measure) questionnaire (Roff, 2005). It is a validated, non-culturally specific generic instrument, used to measure educational environments of undergraduate health professions education. The DREEM inventory consists of 50 items of which nine (9) items are negatively termed statements. The statements are scored along a 5 point Likert scale (4-Strongly Agree, 3-Agree, 2-Uncertain, 1-Disagree, 0-Strongly Disagree). The negative items are scored on reverse order. The total score for the DREEM inventory is 200 .

The five (5) dimensions considered by the DREEM inventory are as follows:

- Students' perception of learning, (12 items, Maximum score 48)

- Students' perception of teachers, (11 items, Maximum score 44)

- Students' academic self-perception, (8 items, Maximum score 32)

- Students' perception of atmosphere, (12 items, Maximum score 48)

- Students' social self-perception, (7 items, Maximum score 28)

Few original items in the DREEM questionnaire were minimally re-phrased maintaining the integrity of the instrument to match the clinical setting to be assessed and to examine true concerns of the related environment in the local setting. The face validity and the content validity of the questionnaire were assessed comparing it to the original tool with the collaboration of an expert in the medical education field. It was pretested on 20 medical undergraduates to check for understanding, clarity and for the presence of ambiguous questions and deficiencies corrected prior to adopting the tool for the study. In addition to the DREEM inventory, students were also asked to respond to two open ended questions: "What are the other factors influencing your clinical performance?" and "What are your suggestions to improve the clinical learning environment?" These questions were included at the end of the DREEM questionnaire. The responses were analysed, and responses were related to the results obtained through DREEM. The final version of DREEM was administered face-toface to the third, fourth and final year medical students of the Faculty of Medicine, University of Kelaniya, Sri Lanka.

The quantitative responses together with demographic data of respondents were 
analysed using SPSS version 14.0. The statistical analysis performed included descriptive statistics to demonstrate the age, gender and seniority distributions of the sample and t-tests and one way ANOVA to compare mean scores of student perceptions with gender and seniority level. The qualitative data, i.e. response to the two open ended questions, were thematically analysed.

Ethical approval for the study was obtained from the Ethics Review Committee, Faculty of Medicine, University of Kelaniya.

\section{Results}

A total of $262(62 \%)$ students representing clinical training years (third, fourth and final year) responded to the questionnaire. The age of the respondents ranged between 21 to 27 years with the mean age of 24.3years. The male to female ratio was 1:2. These demographics were representative of the student population of the medical school.

DREEM Questionnaire
Results of the DREEM questionnaire were analysed to calculate the total DREEM score for different seniority levels and further explored into the scores of subscales and individual items. The overall DREEM score for different seniority levels reflected a more positive overall student perception on their clinical learning environment ( $3^{\text {rd }}$ year-111.78 (SD 16.16), $4^{\text {th }}$ year-113.31 (SD 17.22) and final year-112.17 (SD 20.83)). The scores obtained for subscales by the study population according seniority are shown in Table 1.

As noted in Table 1, four subscales out of five were only one step below the ideal in the four tiered scale demonstrating more positive student perceptions. The subscale on "Students' perception of teachers (SPT)" was found to be two steps below the ideal and was levelled at "In need of some retraining" according to the scale.

One way ANOVA was conducted to determine the relationship between student seniority level and gender with perceived scores for different subscales of the DREEM inventory.

Table 1: DREEM subscale scores according to seniority levels

\begin{tabular}{|c|c|c|c|c|}
\hline \multirow[t]{2}{*}{ DREEM Subscale } & \multicolumn{3}{|c|}{$\begin{array}{l}\text { Mean scores according to } \\
\text { seniority level (SD) }\end{array}$} & \\
\hline & $3^{\text {rd }}$ Year & $4^{\text {th }}$ Year & Final Year & \\
\hline \multirow{4}{*}{$\begin{array}{l}\text { Students' perception of } \\
\text { learning }\end{array}$} & \multirow{4}{*}{$\begin{array}{l}25.07 \\
(4.56)\end{array}$} & \multirow{4}{*}{$\begin{array}{l}25.23 \\
(5.44)\end{array}$} & \multirow{4}{*}{$\begin{array}{l}25.17 \\
(5.47)\end{array}$} & $0-12$ Very Poor \\
\hline & & & & $13-24$ Teaching is viewed negatively \\
\hline & & & & 25-36 A more positive perception \\
\hline & & & & 37-48 Teaching highly thought of \\
\hline \multirow{4}{*}{$\begin{array}{l}\text { Students' perception of } \\
\text { teachers }\end{array}$} & \multirow{4}{*}{$\begin{array}{l}21.33 \\
(3.9)\end{array}$} & \multirow{4}{*}{$\begin{array}{l}19.85 \\
(4.65)\end{array}$} & \multirow{4}{*}{$\begin{array}{l}18.79 \\
(4.49)\end{array}$} & 0-11 Abysmal \\
\hline & & & & $12-22$ In need of some retraining \\
\hline & & & & 23-33 Moving in the right direction \\
\hline & & & & 34-44 Model teachers \\
\hline \multirow{4}{*}{$\begin{array}{l}\text { Students' academic self- } \\
\text { perceptions }\end{array}$} & \multirow{4}{*}{$\begin{array}{l}19.92 \\
(3.55)\end{array}$} & \multirow{4}{*}{$\begin{array}{l}20.28 \\
(3.31)\end{array}$} & \multirow{4}{*}{$\begin{array}{l}20.16 \\
(4.54)\end{array}$} & 0-8 Feeling of total failure \\
\hline & & & & 9-16 Many negative aspects \\
\hline & & & & 17-24 Feeling more on the positive side \\
\hline & & & & 25-32 Confident \\
\hline \multirow{4}{*}{$\begin{array}{l}\text { Students' perception of } \\
\text { atmosphere }\end{array}$} & \multirow{4}{*}{$\begin{array}{l}30.37 \\
(6.36)\end{array}$} & \multirow{4}{*}{$\begin{array}{l}30.42 \\
(6.24)\end{array}$} & \multirow{4}{*}{$\begin{array}{l}30.49 \\
(7.71)\end{array}$} & 0-12 A terrible environment \\
\hline & & & & $\begin{array}{l}\text { 13-24 There are many issues which need } \\
\text { changing }\end{array}$ \\
\hline & & & & 25-36 A more positive atmosphere \\
\hline & & & & 37-48 A good feeling overall \\
\hline \multirow{4}{*}{$\begin{array}{l}\text { Students' social self- } \\
\text { perception }\end{array}$} & \multirow{4}{*}{$\begin{array}{l}16.78 \\
(3.16)\end{array}$} & \multirow{4}{*}{$\begin{array}{l}17.4 \\
(3.11)\end{array}$} & \multirow{4}{*}{$\begin{array}{l}17.54 \\
(2.96)\end{array}$} & 0-7 Miserable \\
\hline & & & & 8-14 Not a nice place \\
\hline & & & & 15-21 Not too bad \\
\hline & & & & 22-28 Very good socially \\
\hline
\end{tabular}


Only "student' perceptions of learning (SPL)" (F $(2,252) \quad=4.03, \quad p<0.05)$ and "students' perception of teachers (SPT)" (F $(2,252)=6.91$, $p<0.01)$ significantly differed according to seniority. Mean perception scores of "learning (SPL)" were increased and perception scores for "teaching (SPT)" reduced with advancing seniority levels. The academic self-perception (SASP) scores of third year students significantly differed with gender $(p<0.05)$; male students' perception on their academic readiness as measured by items under the subscale "Academic self-perception" is less than female students. There was no relationship of gender with other subscale scores for third year students. Similarly, no statistically significant relationship of gender was established for all subscale scores of fourth and final year students.

According to the DREEM scoring guide, scores of 2 or less for individual items indicate problem areas. Therefore, to obtain more details on each subscale, individual items were analysed and items which were perceived negatively by students $($ scores $<2$ ) of all three batches were identified. These items represented all subscales to a variable degree (Table 2).

\section{Table 2: DREEM items with a score of 2 or less}

\begin{tabular}{ll} 
DREEM subscale & Item/Statement \\
\hline Students' perception of learning & (1) I am encouraged to participate in teaching sessions \\
(7) The teaching is often stimulating & (22) The teaching helps to develop my confidence \\
(25) The teaching over-emphasizes factual learning * & (2) The teachers are knowledgeable \\
Students' perception of teachers & (8) The teachers ridicule the students \\
& (9) The teachers are authoritarian* \\
& (39) The teachers get angry in class* \\
(50) The students irritate the teachers* \\
Students' academic self-perceptions \\
(31) I have learned a lot about empathy in my profession \\
Students' perception of atmosphere & (17) Cheating is a problem in this clinical appointment* \\
Students' social self-perception & (4) I am too tired to enjoy this clinical appointment*
\end{tabular}

*-Negative statements 


\section{Open ended questions}

Analysis of responses to the two questions "What are the other factors influencing your clinical performance?" and "What are your suggestions to improve the clinical learning environment?" showed good correlation with most DREEM inventory scores. The following main themes were derived after analysis of student comments.

1. Clinical teaching is more teacher centred and there is less emphasis on student centred learning

This is one of the main concerns of many study participants. According to Table-2, students do not perceive they are encouraged to participate in teaching sessions and have negative thoughts on developing their confidence. This is elaborated more by student comments as:

"Provide more opportunities to ask questions..., consultants should encourage students more..." (Third year female student)

"Stress and fear of getting scolded make clinical training unpleasant..., teachers blame in front of patients and nurses..." (Third year male student),

"If teachers are more kind and friendly, we can learn more..., teachers should try to correct mistakes of medical students not criticise them..." (Fourth year male student)

2. Limited integration of the medical curriculum and information overload

This is another main concern of medical undergraduates from all clinical batches. They request to:

"Organize clinical training with related modules...; clinical rotations should be scheduled with the academic time table..." (Third year male student)

"Before third year clinical training, teach students about history taking and examination..." (Third year male student)

"Hard to achieve the theory part with back to back long appointment" (Third year female medical student)
"Difficult to do modules and clinical training together; miss many things in clinical training" (Fourth year male student)

3. Organization lapses in clinical training

Although structured clinical training is organized by the medical school, students continue to have a negative attitude towards its conduct. They request to:

"Make a schedule for clinical appointments, wasting time in clinical training" (Fourth year female student)

"Provide learning objectives for each clinical rotation..., need better planning of ward classes..." (Final year female student)

"Yellow/pink books should be strictly maintained with better guidelines... outstation appointments should be arranged with best teachers" (Fourth year male student)

4. Minimal opportunity for reflection during clinical training

Following comments demonstrate the limited opportunity for reflection during clinical training.

"Crowded wards with lot of patients allocated to a student make clinical training stressful..." (Fourth year male student),

"Lot of students in a group, can't take maximum benefit of teaching..." (Final year male student)

\section{Negative group dynamics}

Students do not relate well with their peers and complain unsatisfactory student behaviour. Accordingly, students stress the need to:

"Have equal number of girls and boys in a group..., do not group according to registration number but let students group themselves..." (Third year male student)

"Fellow students' behaviour disrupts learning..., it is unfair for the entire group to be punished because of one or two students..." (Fourth year female student) 
"Heavy fighting among students in wards should be stopped..." (Final year male student)

"Interpersonal problems within the group due to stress/ transport from hospital to hostel" (Final year female student).

6. Inability appreciate learning in the community setting

Students have also raised their concerns with high demands of the community health strand and its interference with effective clinical learning. Accordingly they say they are:

"Stressed with community medicine..." (Third year male student)

"Public health lectures should be confined to one term during third year..., and request "to cut down community field visits as it disturbs clinical training..." (Fourth year male student)

\section{The need for student support and} feedback

Students also mentioned their concerns with the available student support. They ask for:

"Student support for failing students as it is difficult to access the system" (Third year male student),

"Arrange discussions on questions after exams..." (Final year male student)

\section{Inadequate physical facilities hamper learning in the clinical setting}

A majority of students at all seniority levels mentioned the need to improve physical facilities in the clinical learning environment. They say:

"It is difficult to concentrate standing for hours during ward classes..." (Third year female student),

"No proper place for students even to eat" (fourth year female student),

Request to "Provide study areas and information access areas for students in wards..." (Fourth year male student),
"A common room for students with lockers..." (Final year male student)

\section{Discussion}

The use of the DREEM inventory in this study provided a valuable overall impression of the current educational environment of the medical school with special emphasis on clinical learning. Furthermore, the analysis of scores of the five subscales of the DREEM inventory, their constituent items along with qualitative comments brought more meaning to the assessment of the clinical learning environment.

The total DREEM scores for students at different seniority levels undergoing clinical training was found to be more positive and the scores were comparable to other medical schools nationally and regionally (Lokuhetty et al., 2010; Abraham et al., 2008; Jiffry et al., 2005). However it also highlighted the considerable scope for improvement in view of scores obtained by medical schools in many developed countries(Avalos et al., 2007; AlHazimi et al., 2004). Furthermore, surprisingly the DREEM scores remained consistent with the previous scores of the medical school obtained a decade ago at early stages of curricular change indicating the persistence of a hidden curriculum resisting intended changes in the new curriculum (Chandratilake \& Silva, 2009).

Analysis of subscale scores demonstrated that students have a more positive perception on their learning; the mean perception is significantly increased with seniority. As found embedded in student comments, this is mainly due to the increased exposure to clinical learning with increasing seniority which enable them to appreciate the application of basic sciences knowledge in practice. However, few problem areas under this subscale having a score of less than $2(<2)$ were identified. These areas highlighted the authoritarian practices of the clinical teaching staff and their disregard for student centred learning. This indicated the necessity to provide continuous support for staff members through staff development activities, making them aware on current trends and practices in the medical education field. It also highlighted the need to re-organize the delivery of current CPD (Continues Professional Development) activities of the medical school reaching even the senior staff members. Furthermore, the need to update clinical staff working under the purview of different administrative structures (e.g. Health Ministry) was identified. The main organizations in the 
country responsible for postgraduate training and continues professional development of medical professionals could play a significant role in introducing the current trends and concepts in teaching and learning.

In addition, the subscale on "student perception of teachers", was also found to significantly differ according to seniority. The mean perception is reduced with advancing seniority and was ranked as "In need of some retraining", two steps below the ideal according to the DREEM subscale interpretation guide. This further elaborated the need for staff development reaching clinical staff.

Analysis of scores of other subscales demonstrated students feeling more positive academically, consider the educational atmosphere is more positive and the social environment is not too bad. There were no significant differences of these subscale scores according to seniority. However, students' academic self-perception significantly differed with gender, third year male students perceiving less than female students. There was no gender difference in other subscale scores at all seniority levels. Although students in general are more positive academically, the mean scores are non-significantly lower among third year students. Being novices to clinical training, they may have difficulty in adapting to the environment and could have led to this finding. Student comments also highlighted the need of more support for third year medical students.

Furthermore, the analysis of student comments revealed few additional problems to what was identified through the DREEM inventory.

Accordingly, students' concern over limited integration of the curriculum was identified. They highlighted the need for better alignment of clinical rotations with the academic time tables and the difficulties faced in coping with academic work with continued training in clinical rotations. They also request for early introduction to clinical training as this will equip them with more competence when following clinical rotations in the third year. These findings demand a curriculum review in order to identify means of reducing the work load and achieving better alignment of clinical training with academic teaching.

Furthermore, students at all seniority levels were concerned with the conduct of clinical rotations. Despite the presence of clinical record books containing learning objectives for each appointment they continued to request for a specific timetable and objectives for clinical rotations to make learning more structured, effective and efficient. The student comments revealed poor maintenance and the lack of adherence to the clinical record book. Therefore, the need to educate the clinical training staff on the importance of organizing clinical rotations as "learning rotations" and the need to align with the objectives of the clinical rotation were identified.

Moreover, the student comments highlighted the limited opportunity for reflection during clinical training. Reflection is an important aspect of learning. It is through reflection that students evaluate their own performances and identify their strengths, weaknesses and areas for improvement (Mamede et al., 2008). The regular allocation of large number of patients for each student have made students over burdened with work, reducing time and opportunity to reflect on their learning. This indicated the need to create clinical rotations more learning oriented than adhering to normal work flow in the clinical setting and the requirement of staff development activities addressing clinical teachers to equip themselves with the necessary knowledge and understanding.

Students also raised concerns on inadequate support extended by the staff and the limited opportunity to obtain feedback following assessments. Although a student mentoring system is already established in the medical school, it seems that student requirements are not being addressed fully by this system. Therefore, looking into formal training of academic staff on mentoring and student support would be worthwhile. Furthermore, making academic staff members available for students at their offices at least once a week would be another option. Making assessments transparent where students are given an opportunity to review their performance at assessments and obtain feedback from staff members should also be looked into. The establishment of a unit for counselling operated by qualified academic staff in the medical school could also be considered to provide services to students troubled with stress.

The analysis of student comments further demonstrated a lack of interest in community health, a strand which introduces the students to common health issues, diverse backgrounds, needs and difficulties faced by people in the community using and accessing the health care system. As community oriented learning is an important concept to be nurtured 
by medical undergraduates it warrants identification of possible measures to make the strand more attractive to students (Hays, 2007). One of the means of achieving this would be to integrate community strand sessions to other modules to make the sessions more relevant to practice. Student orientation to community health can also be made more interesting by introducing more creative events, group work to appreciate the value of community orientation in learning. The assessments of the strand should also be made more practice oriented than theory which will encourage students to participate more in the community work.

Several issues regarding poor infrastructure facilities have emerged from the data analysis. Although the problem is beyond the limits of the medical school, the clinical staff could be informed on the difficulties faced by students during clinical training and to look into possible alternatives to facilitate their learning.

The finding of the DREEM inventory analysis and student comments are indeed critical for facilitating student learning in the clinical setting and preparing them for a better career in health care. Therefore, this study highlighted the leading role to be played by the medical educationists in the medical school with the support of other academic staff and administrators in bridging the identified gaps in the clinical learning environment. It also gave an insight in to the persistence of a vicious circle creating a stressful learning environment for student learning hindering their performance. The inter-relationship of these factors in the current clinical environment and their impact on student learning is diagrammatically presented below. This adds to the findings of Chandratilake and Silva (2009) by emphasising the impact of the clinical learning environment on medical undergraduate learning and how they perform in practice (Figure 1).

In conclusion, the use of DREEM inventory with qualitative input enabled improved understanding of the existing learning environment and revealed problem areas which could not have been identified through the survey alone. Therefore, the incorporation of qualitative comments to the DREEM inventory could be considered as a time and cost effective means of obtaining qualitative insights into a study on assessing the educational environment as a means of understanding its quality gaps for remediation.

\section{Medical school}

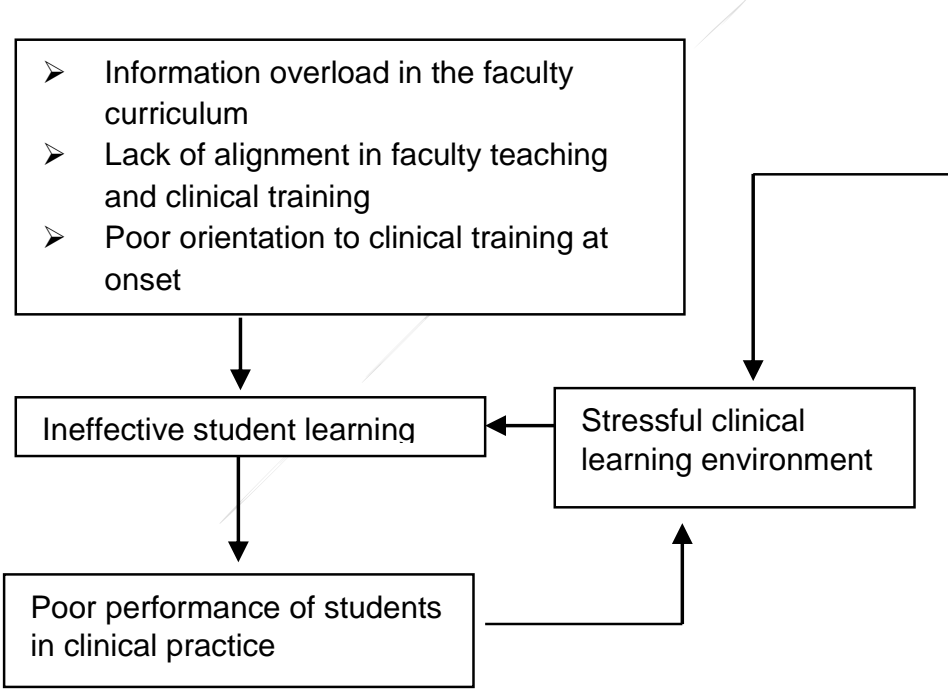

\section{Clinical rotations}

\begin{tabular}{ll}
$>$ & Poorly structured clinical rotations \\
$>$ & Lack of "learning orientation" \\
$>$ & Limited opportunity for reflection \\
$>$ & Authoritarian practices of clinical \\
& teachers \\
$>$ & $\begin{array}{l}\text { Negative group dynamics leading to } \\
\text { disharmony among peers }\end{array}$ \\
$>$ & Poor infrastructure facilities \\
\hline
\end{tabular}

\section{Figure 1: Interrelationship of issues at the clinical and medical school educational environment with student learning and clinical performance}

\section{References}

Abraham, R., Ramnarayan, K., Vinod, P. \& Torke, S. (2008) Students' perceptions of learning environment in an Indian medical school, $B M C$ Medical Education, [online] 8, 1, p. 20. Available 
at:http://www.pubmedcentral.nih.gov/articlerender .fcgi?artid=2329622\&tool=pmcentrez\&rendertype =abstract [Accessed on June 25, 2014].

Al-Hazimi, A., Zaini, R., Al-Hyiani, A., Hassan, N., Gunaid, A., Ponnamperuma, G., Karunathilake, I., Roff, S., McAleer, S. \& Davis, M. (2004) Educational environment in traditional and innovative medical schools: a study in four undergraduate medical schools, Education for health-Abingdon-Carfax Publishing Limited, [online] 17,2, pp.192-203. Available at: http://www.ncbi.nlm.nih.gov/pubmed/15763762 [Accessed on June 25 2014].

Avalos, G., Freeman, C. \& Dunne, F. (2007) Determining the quality of the medical educational environment at an Irish medical school using the DREEM inventory, Irish Medical Journal, 100, 7, pp. 522-525.

Bunyan, M., Boyle, J., Wyse, K., Sutton, N. and Sale, M. (2011) Using the 'DREEM' to assess recovery experiences in two mental health inpatient rehabilitation settings, Clinical Psychology Forum [online], 224, pp.34-38. Available at: http://www.scopus.com/inward/ record.url?eid=2-s2.0-80051706655\&partnerID $=40 \& \mathrm{md} 5=5276035376122 \mathrm{ef} 2255 \mathrm{~d} 8 \mathrm{e} 85883 \mathrm{f} 4 \mathrm{eef}$

Chandratilake, M.N. \& De Silva, N.R. (2009) Identifying poor concordance between the 'planned' and the 'hidden' curricula at a time of curriculum change in a Sri Lankan medical school using the Dundee Ready Education Environment Measure, South East Asian Journal of Medical Education, 3,2, pp.15-19.

Hays, R. (2007) Community-oriented medical education, Teaching and Teacher Education, 23,3, pp.286-293.

Jiffry, M.T.M., McAleer, S., Fernando, S. and Marasinghe, R.B. (2005) Using the DREEM questionnaire to gather baseline information on an evolving medical school in Sri Lanka, Medical Teacher,27,4, pp.348-352.

Lokuhetty, M.D., Warnakulasuriya, S.P., Perera, R.I., De Silva, H.T. and Wijesinghe, H.D. (2010) Students' perception of the educational environment in a Medical Faculty with an innovative curriculum in Sri Lanka, South East Asian Journal of Medical Education, 4,1, pp.9-16.

Mamede, S., Schmidt, H.G. and Penaforte, J.C. (2008) Effects of reflective practice on the accuracy of medical diagnoses, Medical Education, 42,5, pp.468-475

Maudsley, R.F. (2001) Role model and the learning environment:essential elements in effective medical education, Academic Medicine, 76,5, pp.432-434.

Pyke, S.W. and Janz, T.A. (2000) A scale to assess student perceptions of academic climates The CanadianJournal of Higher Education, 30, 1, pp.89.

Roff, S. (2005) The Dundee Ready Educational Environment Measure (DREEM)- a generic instrument for measuring student's perceptions of undergraduate health professions curricula, Medical Teacher, 27,4, pp.322-325.

Roff, S., McAleer, S. and Skinner, A. (2005) Development and validation of an instrument to measure the postgraduate clinical learning and teaching educational environment for hospitalbased junior doctors in the UK, Medical teacher, 27,4 , pp.326-331.

Spencer, J. (2003) Learning and teaching in the clinical environment: How doctors teach experiential learning, British Medical Journal, 326 (March), pp.591-594.

Varma, R., Tiyagi, E. and Gupta, J.K. (2005) Determining the quality of educational climate across multiple undergraduate teaching sites using the DREEM inventory, BMC Medical Education, [online] 5,1, p.8. Available from: http://www.pubmedcentral.nih.gov/articlerender.fc gi ?artid $=553968 \&$ tool $=$ pmcentrez $\&$ rendertype $=a b$ stract [Accessed on June 252014 ].

Wright, A., Regan, M., Haigh, C., Sunderji, I., Vijayakumar, P., Smith, C. and Nestel, D. (2012) Supporting international medical graduates in rural Australia: A mixed methods evaluation, Rural Remote Health, 12, p.1897. 